\title{
Impactos ecosociales de los parques eólicos en el istmo de Tehuantepec, México
}

\author{
Ecosocial impacts of wind farms in the isthmus of Tehuantepec, \\ Mexico
}
Impactos ecossociais dos parques eólicos no istmo de Tehuantepec, México

\section{Domingo Rafael Castañeda Olvera*}

\begin{abstract}
RESUMEN
El presente trabajo de investigación tuvo como objetivo analizar algunos impactos ecosociales resultado de la puesta en marcha de parques eólicos en el Istmo de Tehuantepec, al sureste de México. Buscamos sumarnos al debate respecto de la crítica al modelo económico imperante, que aprovecha el impulso del ambientalismo contemporáneo y la necesidad por encontrar alternativas al desarrollo, para capturar proyectos de generación de energía renovable bajo su lógica mercantilista, profundizando los escenarios de desigualdad en los habitantes de esta región y obstaculizando el combate a la pobreza energética que existe en el país. Abordamos la problemática desde el análisis georreferencial, con la reflexión acerca de la percepción de los pobladores plasmada en diversos artículos periodísticos y la consulta de estudios de la gran biodiversidad de la región. Concluimos que la diversificación de la matriz energética en México debe encontrar mecanismos de inclusión de las comunidades en la toma de decisiones en cuanto a sus territorios, bajo el paraguas del diálogo de saberes, remarcando la necesidad de eliminar la lógica de mercado que cosifica al sistema natural.
\end{abstract}

Palabras clave: conflictos ecosociales, energía eólica, energías renovables, Istmo de Tehuantepec, parques eólicos. 


\begin{abstract}
This research analyzes some Eco-social impacts resulting from the implementation of wind farms in the Isthmus of Tehuantepec, southeast of Mexico. We seek to join the debate regarding criticisms of the prevailing economic model, which takes advantage of the impulse of contemporary environmentalism and the need to find alternatives to development. We seek to capture renewable energy generation projects under its mercantilist logic, deepening the inequality scenarios in this region's inhabitants and hindering the fight against energy poverty in the country. We approach the problem from a georeferenced analysis, reflecting on the inhabitants' perception expressed in various newspaper articles and consultation of studies of the region's vast biodiversity. We concluded that the diversification of the energy matrix in Mexico must find mechanisms to include communities in the decision-making process regarding their territories, under the umbrella of the dialogue of knowledge, stressing the need to eliminate the market logic that reifies the natural system.
\end{abstract}

\section{RESUMO}

Este trabalho de pesquisa teve como objetivo analisar alguns impactos ecossociais resultantes da implementação de parques eólicos no Istmo de Tehuantepec, no sudeste do México. Procuramos entrar no debate sobre as críticas ao modelo econômico vigente, que aproveita o impulso do ambientalismo contemporâneo e a necessidade de encontrar alternativas ao desenvolvimento para captar projetos de geração de energia renovável sob sua lógica mercantilista, aprofundando os cenários de desigualdade dos habitantes desta região e dificultando o combate contra a pobreza energética existente no país. Abordamos a problemática através de uma análise georreferenciada, com a reflexão sobre a percepção dos habitantes apresentada em vários artigos jornalísticos e da consulta de estudos sobre a grande biodiversidade da região. Concluímos que a diversificação da matriz energética no México deve encontrar mecanismos para a inclusão das comunidades no processo de tomada de decisões sobre seus territórios, sob a égide do diálogo do conhecimento, enfatizando a necessidade de eliminar a lógica de mercado que coisifica o sistema natural.
Keywords: ecosocial conflicts, wind energy, renewable energies, Isthmus of Tehuantepec, wind farms.

Palavraschave: conflitos ecossociais, energia eólica, energias renováveis, Istmo de Tehuantepec, parques eólicos. 


\section{Introducción}

Durante la XXI Conferencia de las Partes (COP21) de la Convención Marco de Naciones Unidas sobre Cambio Climático (CMNUCC), las Partes aprobaron el Acuerdo de París con el objeto de reforzar la respuesta global ante el cambio climático y fortalecer los planes de mitigación ante el daño ecosistémico en el planeta, buscando evitar la llegada a los puntos críticos o de no retorno. El objetivo general de dicho acuerdo era generar acciones globales para retrasar la llegada a estos puntos de inflexión, los cuales señalan umbrales que, una vez rebasados, desatarían cambios irreversibles en el sistema regenerativo planetario y colapsarían su capacidad de resiliencia de manera irreversible (European Commission, 2015).

Estos puntos de no retorno están ya activos ${ }^{2}$ según expertos del Panel Intergubernamental de Cambio Climático (IPCC, por sus siglas en inglés), pero serán alcanzados más rápidamente si para finales de este siglo la temperatura del planeta aumenta $2^{\circ} \mathrm{C}$ respecto de los niveles preindustriales (Lontzek, Cai, Judd y Lenton, 2015). Son varios los frentes para detener este fenómeno, pero uno fundamental es la reducción de emisiones de Gases de Efecto Invernadero (GEI) de origen antropogénico, esencialmente aquellos derivados de actividades como la agroindustria y la ganadería, así como el empleo masivo de combustibles fósiles.

Sin embargo, el modelo económico actual se basa en la quema de estos combustibles como fuente predominante para el suministro energético, por lo que la reducción de GEI globales debe apostar no solamente por un cambio en la matriz energética actual -la cual suele externalizar sus costos y efectos-, sino que exige una profunda reflexión acerca de la transformación del sistema extractivista imperante, el cual prioriza el uso excesivo de recursos y energía para man-

2 Se han señalado nueve puntos de inflexión: (1) las sequías frecuentes en la Amazonia; (2) la reducción de área en el hielo Ártico; (3) la circulación más lenta de corrientes en el Océano Atlántico; (4) los incendios y las pestes en el Bosque Boreal; (5) el incremento de la mortandad de las barreras de corales; (6) la pérdida acelerada en el hilo de Groenlandia; (7) el derretimiento de Permafrost; (8) la pérdida acelerada en el hielo en el oeste Antártico; y por último (9) la pérdida acelerada de la Cuenca Wilkes, al este de la Antártica. Estos nueve puntos están biológicamente interconectados y todos ellos han mostrado evidencias de un cambio acelerado en las últimas décadas. Para detalle, véase https://www.nature.com/articles/d41586-019-03595-0 
tener el estilo de vida de las sociedades modernas (Seoane, 2012), un estilo de vida que es ecosistémicamente insostenible.

Las energías renovables, en este sentido, aportarían significativamente en la lucha contra el cambio climático al reducir la generación de GEI y detener así la velocidad de encuentro con estos puntos de no retorno. Las energías renovables son aquellas que se obtienen a partir de fuentes naturales que producen energía de forma inagotable e indefinida (como la energía solar, eólica o mareomotriz, entre otras), o bien, que se regeneran con el tiempo de manera natural (como la masa forestal) ${ }^{3}$. El aprovechamiento sostenible de estas fuentes de energía responde a una suerte geográfica, geológica y climatológica que posibilitaría su uso para las actividades humanas, buscando un equilibrio entre un estilo de vida sostenible y su adaptación a los procesos resilientes del sistema de vida planetario (Brown, 2013).

Por otro lado, es importante recordar que México es un país altamente dependiente de los combustibles fósiles (Puyana, 2015). Sin embargo, sus condiciones geográficas, geológicas y climatológicas le otorgan recursos extensos que permiten pensar en la posibilidad de un cambio de paradigma energético basado en las energías renovables y el abandono de las fósiles, lo cual permitiría no solo cumplir con sus compromisos políticos globales pactados en los Acuerdos de París de 2015, sino (y más importante aún) combatir la pobreza energética que enfrentamos como nación desde hace décadas y reducir así la huella ecológica que trae aparejada la fosilización energética.

Por ello, desde la década de los noventa el gobierno mexicano ha iniciado una transición de modelo energético hacia las energías renovables, aunque ha sido una transición tímida (Oswald, 2017), con arreglos estatales lentos, que no han permitido del todo un ensamblaje del aparato institucional alrededor de las energías renovables con la adecuada creación/implementación de leyes que permitiesen

3 Por su parte, las energías limpias incluyen aquellas que sí dejan una huella ecológica, ya que incluyen a las hidroeléctricas a gran escala (aquellas que suelen modificar el flujo natural de ríos a través de represas, o bien, que ocupan grandes extensiones de tierra), las plantas de energía nuclear o las de energía térmica con procesos de secuestro o captura de carbono. Es este un debate fuerte, ya que las energías limpias, cuyo impacto socioambiental es profundo, son parte de la reforma energética planteada en México (Beltrán, Morera, López y Villeda, 2017). 
un marco de acción certero. Esta transición energética ha apostado por la creación de un escenario de promoción de los recursos naturales que posee nuestro país para la iniciativa privada y las grandes firmas internacionales; estas industrias, bajo la lógica económica imperante de mercantilizar a la naturaleza, han sido objeto de críticas por los efectos ecosociales que han generado (Toledo, 2013).

Así, el modelo de desarrollo de megaproyectos de generación de energía a través de fuentes renovables está siendo arduamente debatido ya que, en esencia, responde a una lógica de mercado que apunta hacia la objetivación y monetización de la naturaleza y sus recursos, así como la sobreexplotación de los mismos, lo que ha generado escenarios de violaciones continuas a los derechos humanos en áreas rurales o aisladas, habitadas en su mayoría por indígenas, campesinos y pobladores originales, quienes poseen una cosmovisión diferente de la que enarbola este sistema productivo, a saber: el capitalismo en su etapa neoliberal.

Como detallaremos más adelante, lo que se debate no es la apuesta por las energías renovables, ni se discute la necesidad de una matriz energética basada en este tipo de energías; se cuestiona la forma en la que estas energías y esta necesidad han sido utilizadas por las multinacionales para obtener beneficios económicos antes que ambientales, con daños evidentes al estilo de vida de los habitantes y los pobladores donde se instalan.

El núcleo de los conflictos socioambientales generados por la puesta en marcha de megaproyectos de energías renovables en nuestro país tiene como base la confrontación de cosmovisiones diferenciadas que, por un lado, enarbola el capital y su visión monetizada de la naturaleza y, por el otro, la de los pueblos originarios respecto de sus territorios y al uso de los recursos naturales que se encuentran ahí. Las culturas indígenas y los campesinos poseen una noción de arraigo al territorio que no se basa en una visión extractiva ni en la objetivación de la naturaleza, por lo que su cultura, su identidad, así como su estilo y ritmo de vida han sido profundamente comprometidos por la llegada/imposición de estos proyectos de desarrollo que, en general, usufructúan con los ecosistemas, en lo que se ha denominado como despojo biocultural (Toledo y Barrera-Bassols, 2008). 
Por ello, el objetivo central de esta investigación fue analizar los impactos ecosociales que los megaproyectos de parques eólicos han traído consigo en los habitantes de la región del Istmo de Tehuantepec, en el sureste mexicano, específicamente en el estado de Oaxaca, que es donde se aloja la mayoría de estos proyectos ${ }^{4}$.

Para lograr nuestro objetivo, dividiremos esta investigación en cuatro partes: un análisis georreferencial de la región del Istmo de Tehuantepec, destacando su compleja biodiversidad; una presentación y análisis de los megaproyectos eólicos en el sureste oaxaqueño; y una reflexión acerca de los impactos ecosociales en el Istmo, así como algunos impactos en la avifauna de la región y la organización comunitaria en respuesta a los megaproyectos eólicos; finalmente, aportaremos algunas reflexiones en las conclusiones finales al trabajo.

Esta investigación busca aportar elementos al debate referente a la pertinencia de la implementación de proyectos de este tipo no solo en la región del Istmo, sino en localidades habitadas por los "pueblos de la Tierra", no con la idea de satanizar la puesta en marcha de proyectos de energías renovables en estas regiones, ni tampoco de romantizar las cosmovisiones de los pueblos originales, pero sí de aportar un punto de vista crítico al modelo de desarrollo imperante que aprovecha el impulso del ambientalismo contemporáneo y la necesidad por encontrar alternativas al desarrollo, de modo de capturar en su lógica mercantilista a estos necesarios proyectos de generación de energía, ya que profundizan escenarios de desigualdad entre quienes habitan estas regiones, generan despojos bioculturales y obstaculizan el combate contra la pobreza energética que impera en esta región en particular, y en México en general.

\section{Análisis georreferencial del Istmo de Tehuantepec: la compleja biodiversidad de la región}

México cuenta con uno de los potenciales eólicos más altos a nivel mundial. De acuerdo con el National Renewable Energy Laboratory estadounidense, se estima que nuestro país tiene un potencial superior

4 Es importante aclarar que la región del Istmo abarca los estados de Oaxaca, Chiapas, Tabasco y Veracruz; abriga hoy en día la mayor concentración de proyectos de parques eólicos en América Latina, aunque en Oaxaca se concentran la gran mayoría de estos. 
a los $44.000 \mathrm{Gw}$ (Elliot et al., 2014). Sin embargo, la Secretaría de Energía, Sener, asegura que este potencial es de $71.000 \mathrm{Gw}$ (Sener, 2012a), pese a que no ha sido del todo aprovechado, ya que en la actualidad a lo largo de nuestro territorio se pueden generar tan solo $61.570 \mathrm{Mw}$ de capacidad en el sistema eléctrico nacional, lo que se traduce en apenas 0,5\% de la energía ocupada en el país (Sener, 2012b).

Debido a sus particularidades geográficas, geológicas y climatológicas, una de las regiones con mayor potencial es la del Istmo de Tehuantepec, en el sureste mexicano, debido a que la velocidad media anual de los vientos excede los $10 \mathrm{~m} / \mathrm{s}$. Para contextualizar este dato, en el mundo se aprovechan vientos de $6,5 \mathrm{~m} / \mathrm{s}$ para la generación de energía a través de este medio (Juárez-Hernández y León, 2014), por lo que el aprovechamiento de este potencial eólico podría generar condiciones suficientes para combatir la pobreza energética que persiste en la región ${ }^{5}$. De acuerdo con la Comisión Reguladora de Energía (CRE), casi el 70\% de la energía eólica producida en México proviene de esta región (Mapa I).

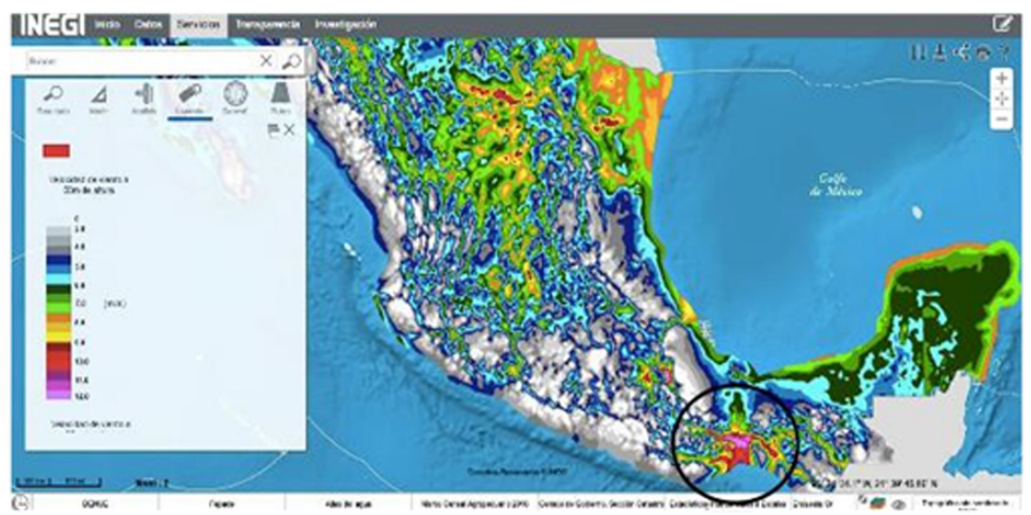

Mapa I. Potencial eólico en la región del Istmo de Tehuantepec.

Fuente: Elaboración propia con base en Inventario Nacional de Energías Renovables, Mapa Digital de México, INEGI 2020.

5 Recordemos que uno de los 17 puntos de los Objetivos de Desarrollo Sostenible (ODS) de Naciones Unidas es la garantía al acceso a energía asequible y no contaminante. Este derecho humano es considerado como un pilar dentro de estos objetivos, ya que su cumplimiento garantiza el logro de otros más (como la reducción de las desigualdades, la vida en ciudades y/o comunidades sostenibles, la acción por el clima, etc.) (ONU, 2015). 
Este potencial eólico se puede transformar en aproximadamente 1.200 watts por metro cuadrado $\left(\mathrm{W} / \mathrm{m}^{2}\right)$, entre los meses de octubre y febrero, cuando la fuerza de los vientos alcanza su clímax en esta región, aunque los estudios demuestran que todo el año se presenta una velocidad de viento superior a la media (Segob, 2015).

Es esta la única región del país que mantiene velocidades por arriba de los $10 \mathrm{~m} / \mathrm{s}$ a 50, 80 y $120 \mathrm{~m}$ de altura ${ }^{6}$. Esta peculiaridad se debe a que es la tercer franja más estrecha del continente - después de la región central de Nicaragua y el Canal de Panamá-, una faja de $200 \mathrm{~km}$ que conecta los océanos Pacifico y Atlántico. Esta estrechez genera lo que se conoce como el efecto túnel, un fenómeno que, a voz de los expertos, ha generado un equilibrio ecosistémico único y, por lo mismo, de muy alta fragilidad ${ }^{7}$.

Esta se explica en parte por la relación que existe entre los diferentes hábitats de la región: en el Istmo confluyen zonas semiáridas donde el ciclo del agua es vital, ya que estos ecosistemas actúan como captadores de humedad, ocasionando que cualquier modificación afecte al equilibrio del resto; también hay regiones costeras y de manglares que inundan las zonas ecotónicas - esto es, fronteras de varios ecosistemas íntimamente relacionados, biológicamente frágiles por combinar zonas acuáticas y terrestres-; hay regiones de equilibrio alrededor de lagunas y humedales cuya función ecosistémica es proporcionar refugio a múltiples especies endémicas y servir de áreas de descanso a las miles de especies migratorias que transitan por la región año tras año (Altamirano, Martín y Cartas, 2001; Cabrera, Mabee y Villegas, 2017; Vázquez, Moya y Arizmend, 2009).

Los especialistas suelen poner especial atención en los casos de la Barra Santa Teresa y Playa San Vicente, zonas de transición de especial relevancia para la región en su conjunto por el equilibrio ecosistémico que proporcionan, ya que lo ocurre en ellos por separado puede afec-

6 Es importante acotar que la altura a la que se instalan los aerogeneradores eólicos es entre 50 y 80 metros, ya que es lo ideal para el funcionamiento de estos dispositivos, tal y como se elaboran hoy en día, aunque ya hay industrias que han elaborado aerogeneradores de hasta 100 metros de altura (Oroschakoff, 2018).

$7 \quad$ Esto en voz de la Dra. Patricia Mora, investigadora del Centro Interdisciplinario de Investigación para el Desarrollo Integral Regional Unidad Oaxaca del Instituto Politécnico Nacional (CIIDIR, Oaxaca, México) (Navarro, 2014). 
tar la dinámica de tal manera que comprometen la existencia de todo el equilibrio de la región en su conjunto ${ }^{8}$.

El cambio climático que opera a nivel global afecta profundamente este tipo de ecosistemas (Durán, Ruiz, González y Martínez, 2020); asimismo, la invasión de estos territorios debido al crecimiento urbano, o bien, por la generación de infraestructura o sistemas tecnocientíficos puede dañar seriamente este frágil equilibrio (por ejemplo, la desaparición de vegetación a través del desmonte elimina especies que sirven como barreras naturales contra corrientes de aire o ante tormentas tropicales o ciclones, lo que además genera el desplazamiento de reptiles, mamíferos pequeños, anfibios, hongos y virus) (García-Trejo y Navarro, 2004; Zárate y Fraga, 2015).

En este sentido, la región del Istmo representa una de las de mayor relevancia biogeográfica debido a la conjunción de flora y fauna propias de las áreas montañosas de clima templado y frío con especies tropicales de clima cálido y húmedo (Mapa II) y ofrece una elevada riqueza de especies de mamíferos, aves, mariposas y especies endémicas (Cortés-Marcial y Briones-Salas, 2014, Howe y Boyer, 2015).

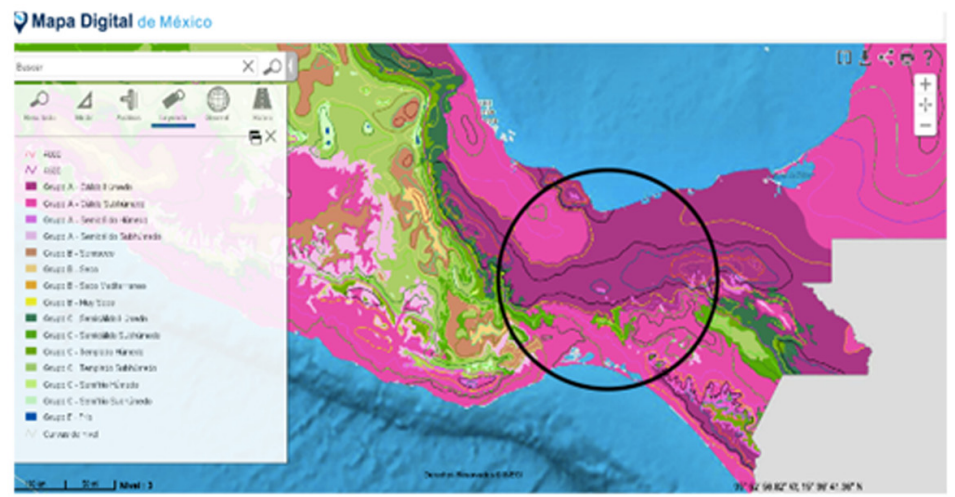

Mapa II. Diversidad climática de la región del Istmo de Tehuantepec.

Fuente: Elaboración propia con base en INEGI (2015), Mapa Digital de México, Carta de Climas, 1:1.000.000.

8 Según ha denunciado la Asamblea de Pueblos Indígenas del Istmo de Tehuantepec en Defensa de la Tierra y el Territorio (APIITDTT), el impacto de los proyectos eólicos en la Barra de Santa Teresa o Bii Hioxho, ubicados en la zona acuífera de la Laguna Superior representaría una profunda amenaza a la soberanía alimentaria de las poblaciones de la región, ya que la puesta en marcha de estos proyectos traería un desequilibrio de la frágil zona manglar (Sipaz, 2013). 
Lo preocupante es que, pese a su gran diversidad, los problemas de conservación abundan, especialmente en sus selvas secas y en los humedales, que son además los ecosistemas más amenazados en el continente (Ceballos y Martínez, 2010).

La comunidad científica especialista en el tema concuerda en la necesidad de elaborar estudios acerca de la compleja biodiversidad de la región para la comprensión de las sinergias ecosistémicas y sus procesos resilientes. Estudios de esta naturaleza servirían como base para el desarrollo de proyectos de desarrollo de cualquier índole en la región y se evitarían Estudios de Impacto Ambiental (EIA) que, generalmente, son criticados y puestos en debate por no considerar esta complejidad, las sinergias y los profundos impactos que se ocasionan al introducir sistemas tecnocientíficos que aprovechan los recursos naturales de la región.

Para finalizar de recalcar la importancia del valor de la biodiversidad de la región, nos parece fundamental resaltar la serie de estudios que han generado planes de conservación con sus normatividades para asegurar la preservación de la biodiversidad, así como el manejo y gestión del territorio en esta región del país.

Con fines metodológicos, en este estudio nos enfocaremos en el estado de Oaxaca, ya que 28 de los 33 parques eólicos ya instalados (o en proceso de instalación) en la región del Istmo de Tehuantepec se encuentran precisamente en ese estado (Semaedeseo, s/f).

En ese tenor, es importante recalcar que cerca del $35 \%$ del territorio oaxaqueño pertenece al programa de preservación Áreas de Importancia para la Conservación de las Aves, AICAS (Comisión Nacional para el Conocimiento y Uso de la Biodiversidad, Conabio, 2004), cuya finalidad es proteger diversas especies de aves en su conjunto. Es este un esfuerzo de gobernanza ambiental continental conformado por especialistas que, con base en estudios de vegetación, topografía e hidrografía, delimitan zonas clave que buscan garantizar la preservación de los ecosistemas donde la avifauna persiste (Mapa III).

Esta delimitación obliga a la Conabio a establecer políticas públicas y leyes que garanticen su preservación (Conabio, 2004). 


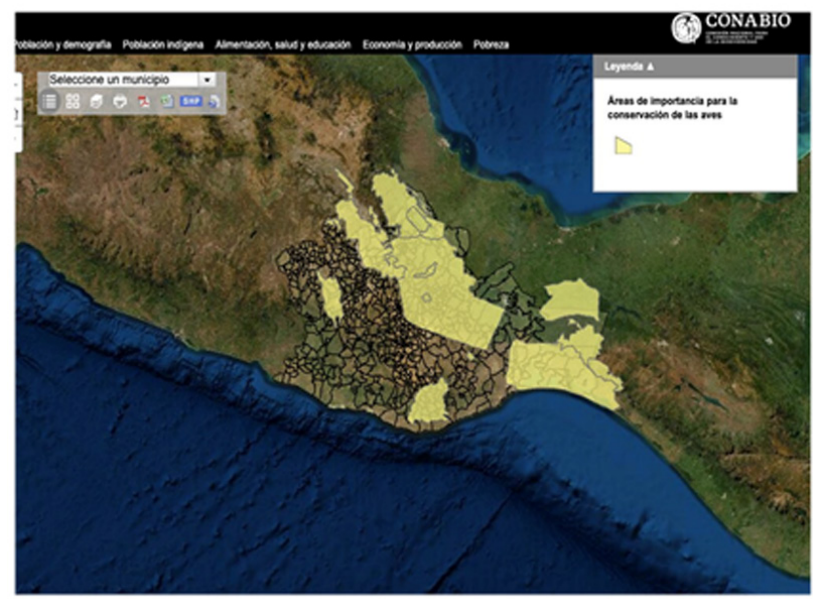

Mapa III. Áreas de Importancia para la Conservación de Aves en Oaxaca. Fuente: Elaboración propia con base en Atlas de Naturaleza y Sociedad, Conabio (2020).

En ese mismo sentido, cerca del $40 \%$ del territorio oaxaqueño está considerado dentro del programa Sitios Prioritarios Terrestres o Regiones Terrestres Prioritarias (RTP), que son sitios con características relacionadas con la biodiversidad, riqueza, endemismo de especies, rareza de tocones, fenómenos ecológicos y evolutivos como migraciones o adaptaciones, o por la rareza en el ámbito global de sus tipos de hábitat, de acuerdo con el estado de conservación y las amenazas a la biodiversidad. Se han identificado sitios de extrema, alta y media prioridad que requieren de manejos sustentable y conservación (Mapa IV).

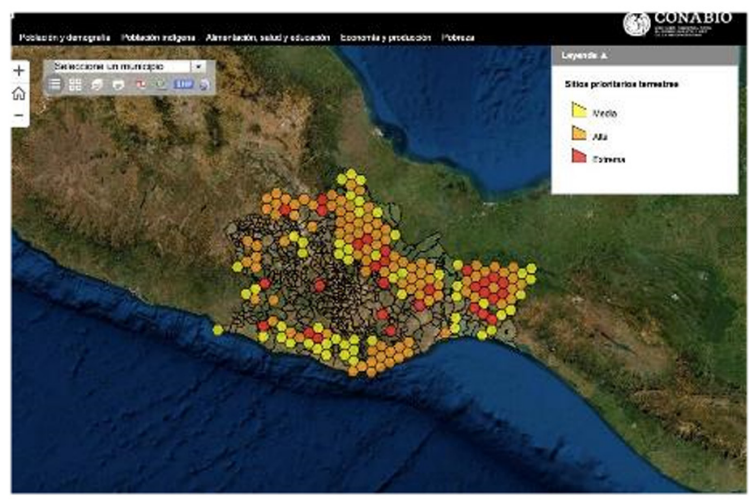

Mapa IV. Sitios Prioritarios Terrestres en Oaxaca.

Fuente: Elaboración propia con base en Atlas de Naturaleza y Sociedad, Conabio (2016). 
Por último, cerca del $80 \%$ del territorio oaxaqueño es considerado como parte del programa Sitios Prioritarios Acuáticos Epicontinentales, esto es, sitios en arroyos, ríos, lagos y lagunas que incluyen una variedad de criterios de importancia como rareza, endemismo, estado de riesgo de extinción (de acuerdo a la NOM-059-SEMARNAT, a la Lista roja de la UICN y a la Alianza para la Extinción Cero) y presión por comercio internacional (CITES); además, para esta clasificación se consideraron áreas de alta riqueza de especies, por lo que se han identificado sitios de extrema, alta y media prioridad que requieren medidas de manejo sustentable y conservación (Mapa V).

Nos gustaría finalizar este apartado señalando que, pese a la diversidad de estudios enfocados en la región ${ }^{9}$, urge analizar el impacto de este tipo de proyectos eólicos en las 795 diferentes clases de mamíferos que se conocen en la zona, en las más de 8.000 clases de insectos, 240 de hongos o en las 3.270 especies de plantas registradas en el área (Sistema Nacional de Información sobre Biodiversidad, SNIB (2020).

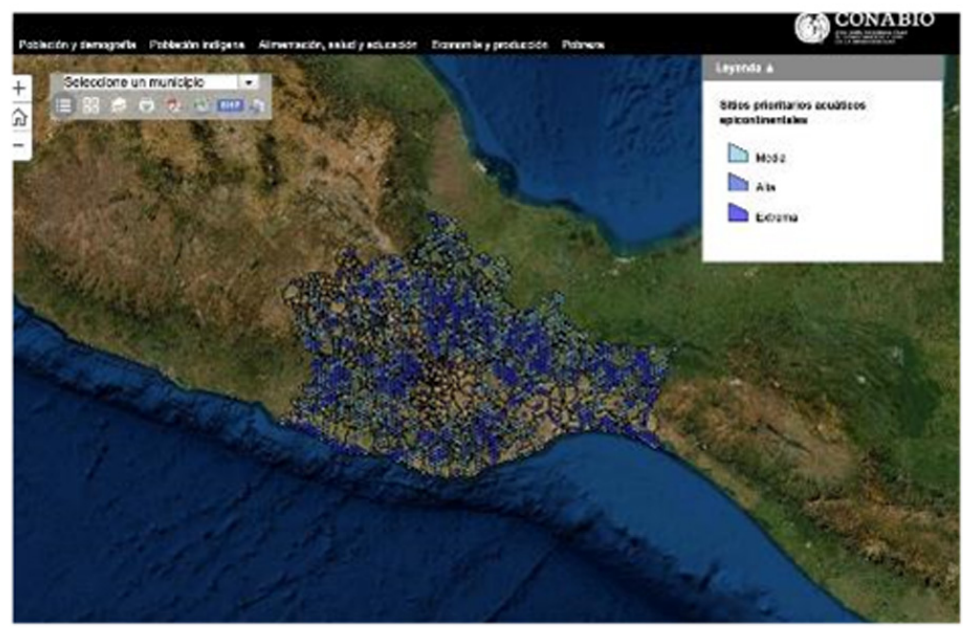

Mapa $V$. Sitios Prioritarios Acuáticos Epicontinentales.

Fuente: Elaboración propia con base en Atlas de Naturaleza y Sociedad, Conabio (2016).

9 Por ejemplo, gracias al valioso monitoreo biológico que se ha implementado en Oaxaca, se ha comprobado que en la región habitan cinco de las seis especies de felinos que viven en México: jaguar, puma, tigrillo, lince y leoncillo (El Universal, 2018). 
Sería menester, pues, establecer planes de protección que garantizaran su preservación ante la llegada de proyectos de desarrollo que han demostrado seguir una lógica extractivista y de despojo biocultural, pese a enarbolar un discurso ambiental, de preservación y baja huella de carbono, minimizando la serie de impactos ecosistémicos que, hasta ahora, se han venido reportando en México y alrededor del mundo.

\section{Megaproyectos eólicos en la región del Istmo de Tehuantepec}

En la actualidad, en lo que se denomina como el Proyecto Eoloeléctrico del Corredor Eólico del Istmo de Tehuantepec existen 28 parques eólicos (Semaedeso, s/f), impulsados en su mayoría por grandes empresas nacionales y transnacionales, que han recibido la colaboración de las instituciones gubernamentales mexicanas e instituciones financieras internacionales como el Banco Interamericano de Desarrollo (BID).

En total, ocupan ya una superficie de alrededor de 60.000 hectáreas de propiedad colectiva, donde se han instalado cerca de 1.650 turbinas, con una generación que ronda los 2.500 y $2.700 \mathrm{Mw}$, según la Secretaria de Turismo y Desarrollo Económico del estado de Oaxaca (El Universal, 2020a).

Es importante señalar que esta región está compuesta por seis municipios: Ixtaltepec de Asunción, que cuenta con 14.751 habitantes; el Espinal, con 8.310; Santa María Xadani, con 7.781; Unión Hidalgo, con 13.683; Santo Domingo, con 7.554; y Juchitán de Zaragoza, el más poblado de todos, con 74.825. De los casi 130 mil habitantes de la región, $80 \%$ son de origen indígena y solo el $30 \%$ habla español. El resto habla una de las seis lenguas indígenas que aún prevalecen en la región (INEGI, 2015).

Por otro lado, los proyectos eólicos en la región empezaron en 1997, cuando la Comisión Federal de Electricidad (CFE) inauguró en Juchitán de Zaragoza el primer parque eólico, La Venta, bajo la figura de Obra Pública Financiada. Desde entonces, se han instalado en la región 28 parques eólicos, con una capacidad nominal de generación que gira entre 2.500 y 2.700 Mw (Tabla 1) (Semaedeso, 2016). 


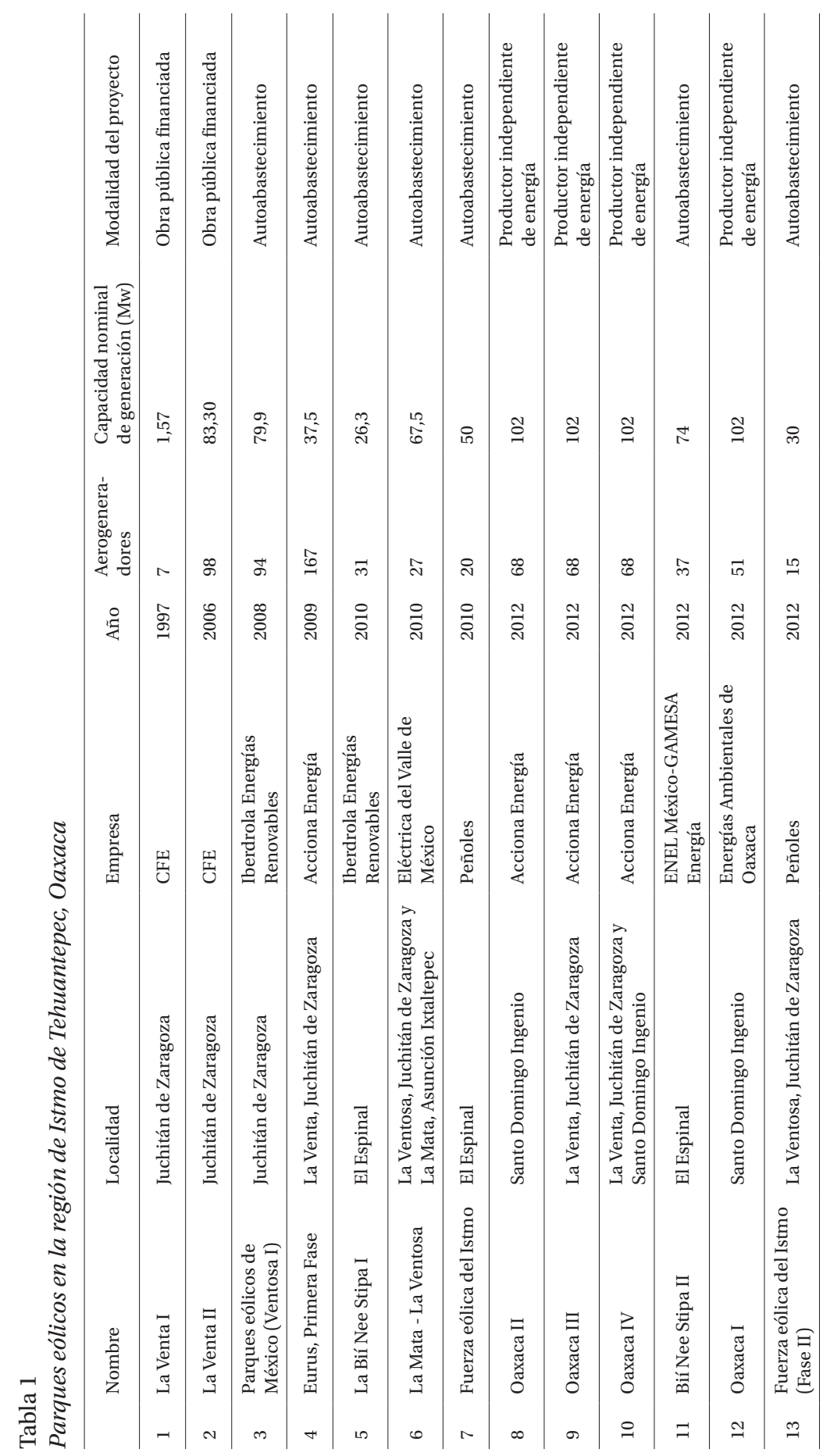




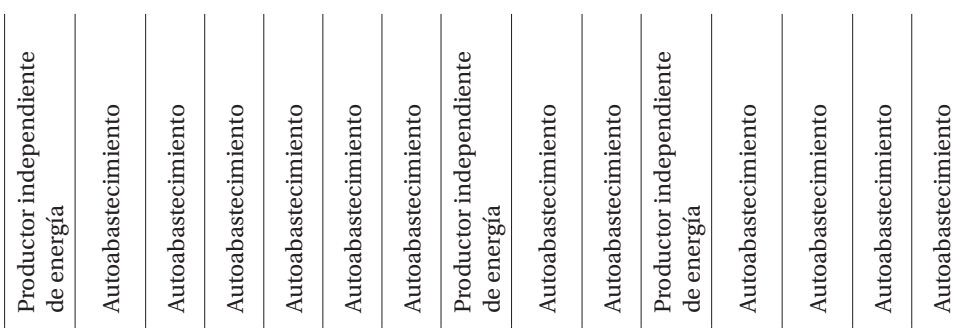

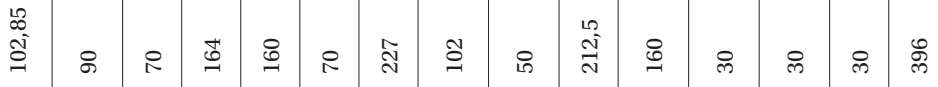

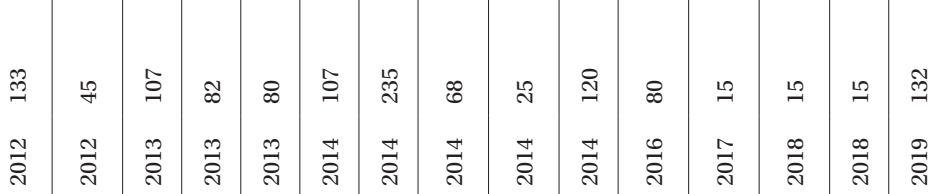

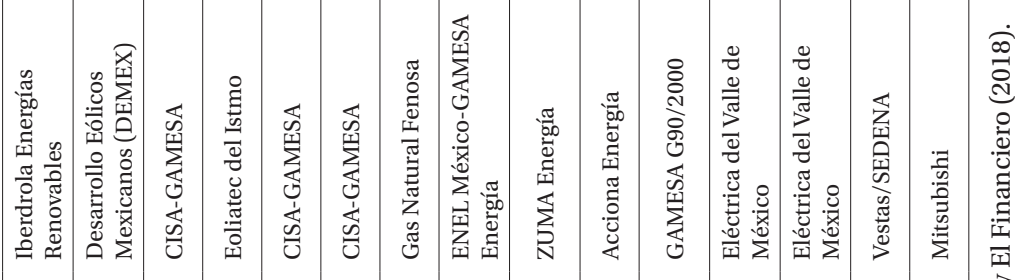

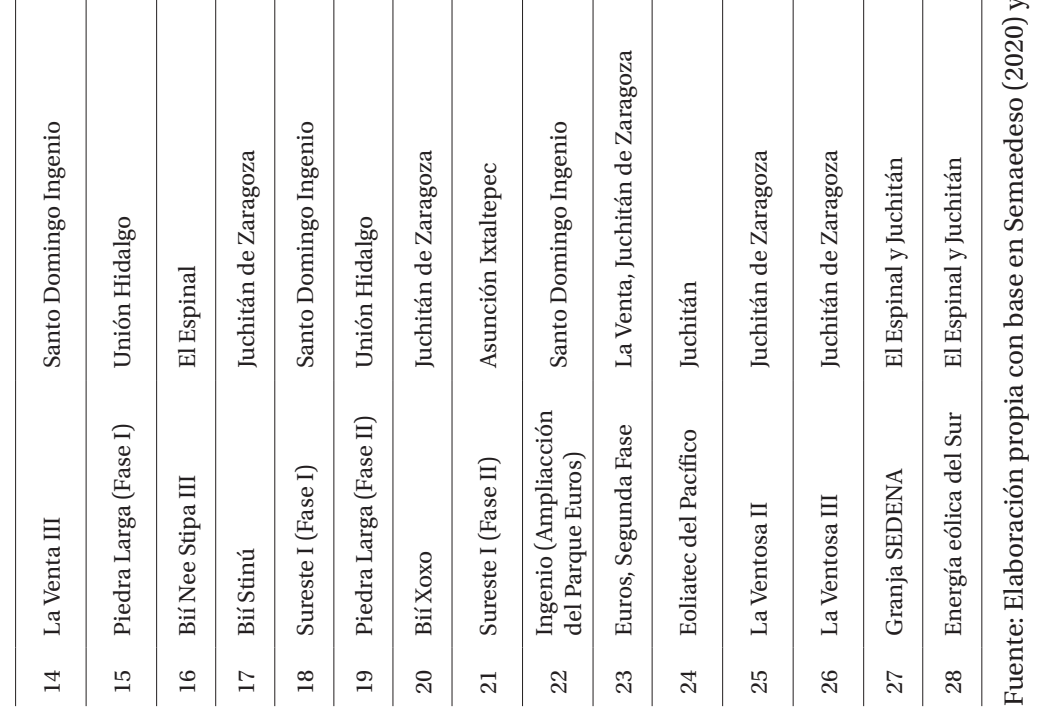


Desde 2006 a la fecha el crecimiento de proyectos eólicos en la región ha crecido de manera exponencial, con una inversión estimada de $\$ 5.000$ millones de pesos mexicanos (Forbes México, 2020). Solo dos de estos parques están bajo el control de la CFE y tres más poseen un control mixto (empresas mexicanas con capital extranjero); las restantes (el 75\%), están bajo control de capital extranjero.

Sumado a esto, gran parte de la tecnología necesaria para la generación de energía en los parques, como los aerogeneradores, son fabricados únicamente por empresas extranjeras de España (Gamesa y Acciona), Dinamarca (Vestas) y EE.UU. (Clipper), lo que implica una profunda dependencia tecnológica, sin mencionar la pérdida paulatina del control gubernamental sobre la gestión de los recursos energéticos, así como de sectores energéticos de la economía nacional (Uharte, 2015).

Ahora bien, la literatura alrededor de la serie de impactos ecosociales aún debate respecto del uso de algunas categorías e indicadores para generar análisis más completos, ya que hay condiciones que pueden variar de país a país e incluso de región a región (Agatón, Santiago, Sautto y Montaño, 2016; Castillo, 2011; Díaz, 2015; Grunstein-Dickter, 2016; Guijarro, Lumbreras, Habert y Guereña, 2009).

El punto central de este debate se enfoca en localizar aquellos elementos que puedan mostrar de qué manera proyectos de gran alcance, como lo son los parques eólicos, pueden afectar significativamente tanto el estilo de vida de las comunidades, como el ecosistema en su conjunto, en el entendido de que la cosmovisión de estos pueblos suele encontrar en el territorio un elemento que forja su identidad, su apego y su cultura. El uso que estos pueblos hacen de sus recursos no empata con la idea de que la naturaleza provee servicios ambientales al ser humano, tal como lo observa la visión capitalista/extractivista, sino que observan esta relación desde una noción de equilibrio y sentido comunitario (Howe y Boyer, 2015; Sánchez, 2010; Toledo, 2013). Por ello, se ha hecho un llamado para que, en el análisis acerca de las posibles afectaciones socioambientales y la generación de categorías de análisis e indicadores de medición de impacto ambiental, se tome en cuenta la voz de indígenas y de pobladores originales, quienes poseen un conocimiento diferente al que provee el método científico moderno, siendo ambas visiones igualmente válidas (Díaz, 2015; Toledo y Barrera-Bassols, 2008). 
Por su lado, algunos acercamientos a esta problemática apuestan porque la implementación de proyectos de carácter ambiental en suelos donde las comunidades originarias han existido desde siempre requieren de la combinación de tres factores: la construcción de confianza, el respeto a las nociones de justicia distributiva y procedimental, así como la consideración del apego a sus tierras (Hall, 2017). Sin embargo, en nuestro país hasta ahora no ha sido documentado un ejemplo exitoso donde algún proyecto de este tipo haya sido implementado con el consenso de la población.

Varias son las aristas de análisis entonces: la falta de consulta a las comunidades y, en todo caso, un debate respecto de la pertinencia del uso de este mecanismo entre grupos sociales que se organizan y deciden de otras formas; la falta de transparencia en los alcances de los proyectos; el incumplimiento de las expectativas: laborales, económicas, energéticas, etc.; la privatización de los recursos energéticos; las repercusiones profundas en el estilo de vida comunitario y el despojo biocultural, entre otras.

Para nuestro estudio de caso, analizaremos brevemente los impactos socioambientales desde el estudio de tres fenómenos: el conflicto por la propiedad y el uso de la tierra, lo que ha generado división de las comunidades y la destrucción del tejido social; la alteración que ocurre debido al funcionamiento mismo de los aerogeneradores y sus impactos en la avifauna de la región; y los conflictos derivados del proceso de compra/venta y arrendamiento de terrenos.

\section{Conflicto por la propiedad y el uso de la tierra}

La situación de la tenencia de la tierra se ha convertido en el mayor problema en estas comunidades a raíz de la implementación de los megaproyectos eólicos. Es también la razón principal de la división que hoy en día existe en estas comunidades. Para ello, debemos hacer hincapié que la cosmovisión de estos pueblos no empata con la percepción mercantilista de la naturaleza y sus recursos, por lo que la imposición de proyectos de esta índole, que les obliga a percibir su territorio en tanto valor de cambio, trastoca profundamente el sentido de equilibrio que poseen estas comunidades con sus tierras y lo que ella les provee. 
Una de las más grandes afectaciones que se les ha hecho a los pobladores de la región es que se han violado sus territorios y se han destruido lugares sagrados y con un profundo significado simbólico ${ }^{10}$, quienes en afán de defender sus rituales y su memoria apegados al territorio, en repetidas ocasiones han sido criminalizados y acusados como opositores al progreso, estigmatizándolos ${ }^{11}$.

Por otro lado, un elemento que se suma al conflicto por la propiedad y el uso de las tierras es que las comunidades, acostumbradas a resolver los asuntos de manera colectiva y pausada, han visto cómo las empresas no comulgan con la idea de hacer asambleas comunitarias para tratar los asuntos relacionados con la puesta en marcha de sus proyectos y el posible impacto en sus territorios. La visión democrática occidental, aquella que opera bajo el principio de la decisión por mayoría, no encaja con la forma comunitaria de la toma de decisiones, mucho menos con los tiempos pausados con los que estas comunidades perciben un proceso de decisión grupal. Por ello, muchas veces han negociado individualmente cada contrato, lo que ha generado divisiones al interior de las comunidades, ya que se han documentado formas persuasivas sobre la base de promesas y expectativas entre ciertos sectores de la población: una de ellas, es la generación de fuentes de empleo bien remuneradas, promesas que inciden en el pensamiento sobre todo de la población más joven en las comunidades, que percibe estas posibles fuentes de empleo como una expectativa de desarrollo y movilidad económicos. Sin embargo, ya se ha documentado que las fuentes de empleo que generan estos megaproyectos son solo temporales (Juárez-Hernández, 2014), reducida a labores como la de obreros y peones, los cuales, además, deben estar afiliados a las centrales obreras y campesinas oficiales (Confederación de Trabajadores de México y Confederación Regional Obrero Campesina) o inclusive a algún partido político (Zárate y Fraga, 2015).

Como resultado de esto, los pobladores opinan que se ha incrementado la corrupción de los dirigentes sociales, quienes han recurri-

10 Por ejemplo, lo sucedido en la Isla Tileme, en la Barra de Santa Teresa, al sureste del Istmo (Desinformemonos.org, 2019).

11 En este sentido, cabe resaltar la historia de las mujeres $i k o o t s$ (o wabes), quienes han fungido como grandes opositoras a estos megaproyectos, pero a la vez, han sido duramente violentadas (El Universal, 2020b). 
do a tácticas intimidatorias para obligar a la firma de las concesiones entre aquellos que no están de acuerdo con la instalación de los aerogeneradores en sus tierras, ocasionando un clima de confrontación al interior de las comunidades y de las asambleas mismas, resquebrajando gravemente el tejido social.

Ha sido también documentada la alteración a la capacidad productiva de los terrenos ejidales en la región (Déniz, De la Rosa y Verona, 2012; Díaz, 2015; Diego, 2017; Guijarro et al., 2009; Sánchez, 2010), ya que durante su instalación, los caminos que se crean para el tránsito de las turbinas, así como para su mantenimiento, han dividido parcelas. Además, en estas regiones persiste el riego por gravedad, actividad agrícola que ha sido interrumpida por la construcción de caminos y el corte de veredas, o bien, por la adaptación de los suelos para el levantamiento de los parques. Como resultado, se ha reportado un mayor número de inundaciones al interferir con el curso natural de los cauces (Navarro y Bessi, 2014), así como el aumento en los procesos erosivos en la región (Agatón et al., 2016).

En este sentido, es importante recalcar cómo los impactos se dan a dos escalas de tiempo. La primera sería el impacto directo, es decir, al instalar el parque, ya que se requiere el "desmonte" de vegetación, que implica la destrucción de plantas y de organismos sésiles - aquellos que no tiene un órgano que sirva de pie o soporte-, con el desplazamiento de reptiles, mamíferos, aves, insectos y aves, etc., que esto significa. La segunda afectación, la más profunda a voz de los expertos, es aquella que se da no en organismos macro, sino en los microorganismos, muchos de los cuales aún no han sido estudiados y clasificados; estos organismos son los que mantienen los sistemas vivos y en equilibrio.

Por último, ya finalizada la construcción, continúa el impacto indirecto debido a la alteración y fragmentación ecosistémica y al cambio de uso de suelo, lo cual aumenta las probabilidades de desaparición de especies y el resquebrajamiento del equilibrio (Navarro y Bessi, 2014). En este sentido, nos parece fundamental comprender cómo perciben y cómo valoran algunos pobladores la puesta en marcha de los parques eólicos (Tabla 2).

Por último, hay algunos indicadores que, pese a ser ya observados en estudios no solo en México, sino en otras latitudes respecto de la 
afectación de los aerogeneradores en la vida cotidiana (Ayuntamiento de Dúrcal, Adurcal, s/f; Nómada, 2018; Process Industry Forum, s/f) (ruido, electromagnetismo, efecto discoteca ${ }^{12}$, etc.), aún no existen evidencias concluyentes, pese a que los pobladores refieren de manera continua afectaciones psicológicas que no pueden explicar (alteraciones en el estado de ánimo, en el sueño, en la percepción de los sonidos de sus animales, etc.), así como variaciones en el comportamiento de sus animales domésticos y de lo que se obtiene de ellos (baja producción de leche, cambios en el sabor de la carne de sus animales de cría, variación en los ciclos de ordeña, etc.). Es un llamado a estudios que profundicen en estos elementos que, al cruzar dos mundos de interpretación, debe hacerse desde el diálogo de saberes.

Tabla 2

Valoración del impacto social de los parques eólicos en la zona de influencia

\begin{tabular}{|c|c|c|c|c|}
\hline AFIRMACIONES & $\begin{array}{l}\text { Totalmente en } \\
\text { desacuerdo/ } \\
\text { en desacuerdo }\end{array}$ & $\begin{array}{l}\text { No sabe/no lo } \\
\text { tiene definido }\end{array}$ & $\begin{array}{l}\text { Totalmente de } \\
\text { acuerdo/de } \\
\text { acuerdo }\end{array}$ & $\begin{array}{l}\text { Grado de } \\
\text { acuerdo }\end{array}$ \\
\hline $\begin{array}{l}\text { Se dio información completa } \\
\text { y se consultó a los pueblos } \\
\text { y comunidades indígenas } \\
\text { antes de la instalación del } \\
\text { parque }\end{array}$ & 73,9 & 1,4 & 24,6 & 3,7 \\
\hline $\begin{array}{l}\text { Estos proyectos han } \\
\text { aumentado la división de } \\
\text { los ejidos }\end{array}$ & 11,6 & 2.9 & 85,5 & 8,2 \\
\hline $\begin{array}{l}\text { Se ha incrementado la } \\
\text { corrupción de los dirigentes } \\
\text { sociales }\end{array}$ & 8,6 & 1,4 & 89,8 & 9,1 \\
\hline $\begin{array}{l}\text { El valor de las tierras se ha } \\
\text { incrementado }\end{array}$ & 23,2 & & 76,8 & 7,8 \\
\hline $\begin{array}{l}\text { El pago por el } \\
\text { arrendamiento de la tierra } \\
\text { para la construcción de las } \\
\text { torres es justo }\end{array}$ & 75,4 & 2,9 & 21,7 & 2,6 \\
\hline $\begin{array}{l}\text { La producción agropecuaria } \\
\text { en nuestra tierras ha } \\
\text { mejorado }\end{array}$ & 84,8 & & 15,2 & 4,6 \\
\hline $\begin{array}{l}\text { Solo los que rentan sus tierra } \\
\text { son los beneficiados del } \\
\text { parque eólico }\end{array}$ & 10,1 & & 89,9 & 8,8 \\
\hline
\end{tabular}

Fuente: Elaboración propia con base en Agatón et al., 2016.

12 Fenómeno que generan las sombras proyectadas por las aspas cuando el sol está por detrás, proyectándose en jardines y ventanas. Para mayor detalle, Duchamp (2004). 


\section{Alteración de la avifauna de la región debido a los aerogeneradores}

En tanto Corredor Biológico, la región del Istmo de Tehuantepec representa una zona de gran relevancia ecosistémica al ser un área de transición de bioma: sus fuertes vientos, el clima semiárido y la poca precipitación pluvial han conformado una serie de hábitats complejos y variados que se extienden desde las llanuras costeras hasta las selvas bajas, lo que genera escenarios propicios para una enorme biodiversidad.

Pese a la diversidad de estudios de la región, esta ha sido poco documentada (Naturalista, 2018; Philofauna, s/f). Una pieza clave para comprender esta complejidad es la composición de la avifauna en la región. Y es que tanto los científicos como los defensores de la Tierra, así como las instituciones especializadas en la región aseguran que hay un alto porcentaje de especies en el Istmo que aún está fuera del radar de sus investigaciones y que, por tanto, se desconocen en alto grado las relaciones sinérgicas que establecen con especies ya estudiadas (García-Trejo y Navarro, 2004; Henestroza, 2009; Howe y Boyer, 2015; Vázquez et al., 2009).

En la región interactúa una enorme diversidad de avifauna, siendo las más importantes las aves medianas, como los apodiformes (de las 366 especies registradas en México, en el Istmo hay 297: colibríes, vencejos, etc.), los piciformes (de las 147 especies registradas en México, en la región hay 140: tucanes, pájaros carpinteros, etc.), psittaciformes (de las 150 especies, en la región existen 130: loros, pericos, cacatúas, etc.), aunque también se involucran aves de mayor tamaño como los accipitriformes (que de las 97 especies en México, en la región se han encontrado 67: águilas, aguilillas, gavilanes y buitres) y los anseriformes (que de 35 especies en nuestro país, en el Istmo hay 21, como patos y gansos) (SNIB, 2020).

Estas dos últimas clasificaciones son sumamente importantes porque se trata de especies que se caracterizan por tener procesos migratorios extensos, algunas hacia el norte del continente, otras más hacia Centro y Sudamérica, por lo que el equilibrio en la región es fundamental para garantizar las condiciones de tránsito que requieren.

Así, el Istmo de Tehuantepec es reconocido como una de las zonas migratorias de avifauna más importante del mundo; algunos estudios 
realizados por instituciones de la región (Instituto Tecnológico del Istmo, ITI, 2016) y otros más por organismos internacionales especializados (Philofauna, s/f) aseveran que cada temporada por esta región atraviesan alrededor de 12 millones de aves de 130 especies diferentes, aunque algunas otras investigaciones aseguran que puede ascender hasta más de 15 millones (Elías, s/f).

Muchas de estas aves están en serio peligro de extinción, como el aguililla de alas anchas, la aguililla migratoria mayor y el halcón peregrino, aves protegidas por las leyes mexicanas, estadounidenses y canadienses; su riesgo aumenta con los parques eólicos, ya que son especies de vuelo bajo, entre 40 y 120 metros de altura, misma a la que son instalados los aerogeneradores (El Universal, 2011).

Estas aves aprovechan el "efecto túnel" que la región posee para establecer su zona de refugio, de alimentación y de descanso durante sus largos trayectos migratorios; el temor de la introducción de sistemas tecnocientíficos invasivos es que generen desequilibrios que trastoquen esta complejidad, esencialmente la de este paso migratorio avifáunico.

$\mathrm{Al}$ ser un fenómeno relativamente reciente, hay poca información acerca del tema de la muerte de aves por los aerogeneradores en Méxi$\mathrm{Co}^{13}$, aunque algunos aseveran que esta pérdida de aves en la región ya alcanza las 200.000 aves y 300.000 murciélagos ${ }^{14}$.

Existen algunos estudios respecto del decremento de la población de aves en EE.UU. (Garvin, Jennelle, Drake y Grodsky, 2011) y Noruega (Dahl, Bevanger, Nygard, Roskaft y Stokke, 2012). En ellos, el fenómeno se asocia tanto a la construcción de las redes de transmisión como, por supuesto, a la instalación de los aerogeneradores. Pese a ello, la muerte

13 Uribe-Rivera, Guevara-Carrizales y Ruiz-Campos (2019) hacen un reporte de parques eólicos en La Rumorosa, Baja California, entre 2015 y 2016; Villegas y Herrera (2015) han estudiado el caso de la gaviota, y aseveran que mueren entre 6.000 y 23.000 ejemplares al año por colisión con turbinas. En Europa hay estudios más avanzados sobre el tema: en España, por ejemplo, con cerca de 18.000 generadores en funcionamiento, se calcula que hay entre 6 y 18 millones de aves muertas (Energías Renovables, 2012); en Nueva Zelanda, la Agencia de Conservación de Aves asevera que al año mueren cerca de 500.000 especies (Powlesland, 2010).

14 Hay que recordar que una de las funciones ecosistémicas más importantes de los murciélagos es la polinización y la dispersión de semillas, hecho que a mediano plazo tendría un profundo impacto en el equilibrio de los hábitats del Istmo. 
por colisión es un tema debatido, con poco consenso. Algunos estudios en Holanda reportan 1,2 aves muertas por turbina al año; seis en Inglaterra; y hasta 23 en Bélgica (Drewitt y Langston, 2006); en EE.UU., los números varían de tanto en tanto: 7,5 en estados como Tennessee; 2,2 en California; y 3,6 en Washington (Kaldellis, Apostolou, Kapsali y Kondili, 2016). Tal variación - y de ahí la falta de consenso-, se debe a la variabilidad en los factores: la conducta de las aves en cada región, su comportamiento reproductivo y alimenticio, la dirección y fuerza de los vientos locales, la topografía del sitio, la luz que logran emitir las turbinas (lo cual puede ser un factor que aumente el riesgo de colisión en condiciones adversas como niebla o lluvia), el tamaño del parque, el número de turbinas instaladas, etc. (Wang y Wang, 2015).

$\mathrm{Al}$ carecer de esta clase de estudios referentes a la colisión de aves en los aerogeneradores en México, el problema ha sido minimizado e invisibilizado en, por ejemplo, los estudios de impacto ambiental presentados por las diversas empresas para llevar a cabo sus proyectos eólicos (González, Ossa, Silva y Sánchez, 2014).

Con 28 parques eólicos funcionando en la región, con cerca de 1.700 aerogeneradores en operación, nos parece fundamental que este elemento sea resaltado como una de las principales afectaciones medioambientales directas de los proyectos de parques eólicos, al lado de fenómenos como el desplazamiento de especies por modificación de hábitat, el efecto barrera y la pérdida misma de hábitat. Debemos recordar, también, que para la puesta en marcha de un parque eólico se requiere la eliminación de cobertura vegetal, fenómeno que a su vez genera la fragmentación del hábitat que, debido a los procesos cíclicos naturales, en algún momento afecta el frágil equilibrio de la región.

En suma, nos parece que no hay estudios que garanticen la preservación del ecosistema del Istmo con la introducción de sistemas tecnocientíficos, por lo que la densidad del proceso migratorio mismo está en riesgo. Urge así la generación de información e involucrar a instituciones gubernamentales, empresas, centros de investigación y a los protectores de la Tierra, quienes conocen las rutas migratorias de las aves, sus comportamientos sinérgicos, sus sitios de refugio, las relaciones con la flora de la región, así como las afectaciones profundas que perciben ya en sus territorios. 


\section{Conflictos por proceso de compra/venta y arrendamiento de terrenos}

Por último, un punto de alta conflictividad se ha dado por la forma en la que se genera el proceso de compra-venta/arrendamiento de los terrenos. Se han registrado ya una gran cantidad de firmas de contratos en un lenguaje ajeno a los indígenas ya que, como mencionamos al iniciar este apartado, $80 \%$ de la población en la región es indígena y solo el $30 \%$ habla español, por lo que muchas veces estas sesiones de firmas se dan sin consentimiento previo o aprovechándose de la confusión y de la mala información, del dolo y la mala fe al entregarse contratos a personas analfabetas y sin abogados de por medio (Castillo, 2012); los contratos, además, cubren un periodo de 30 años con un pago aproximado de $\$ 12.500$ pesos mexicanos anuales por hectárea (aproximadamente US\$650 dólares, mientras que en España se pagan cifras entre los US $\$ 5.000$ y US $\$ 9.000$ dólares anuales ${ }^{15}$ ), sin que existan clausuras por actualización de los pagos (Navarro y Bessi, 2014).

Estos contratos, además, se renuevan automáticamente por 30 años más y se puede ampliar por otros 30, si el comprador así lo desea. En este mismo sentido, el Centro de Derechos Humanos Digna Ochoa, de la Costa de Chiapas, advierte de la falta de información y claridad de los contratos realizados, en muchas ocasiones firmados bajo presión de las empresas, motivo por el cual ha recibido constantemente quejas por actos de criminalización, amenazas y agresiones a los pobladores que se oponen a los megaproyectos (Barragán, 2015).

Bettina Cruz, vocera de la Asamblea de los Pueblos del Istmo de Tehuantepec en Defensa de la Tierra y el Territorio (APITDTT), afirma que la estrategia de las corporaciones incluye también la "compra de voluntades", tanto de los gobiernos estatales como, y sobre todo, de las autoridades locales, quienes a través de sobornos aseguran el otorgamiento de permisos. A su vez, afirma la vocera, la forma de asegurarse que la estrategia funcione es aplicar esta estrategia de com-

15 Véase Código DH, Colectivo Oaxaqueño en Defensa de los Territorios, Red Nacional Todos los Derechos para tod@s, Red Nacional de Comunicación y Acción Urgente de Defensoras de los Derechos Humanos en México, Proyecto de Derechos Económicos, Sociales y Culturales, A.C., Oficina Ecuménica por la Paz y la Justicia de Múnich, Amnistía Internacional. 
pra de voluntades también a las autoridades civiles y agrarias locales, quienes representan el eslabón más débil en la cadena de decisiones estatales. La líder indígena asevera también que hay una constante en el incumplimiento de las normativas locales de toma de decisiones, normativas que tienen como sustento tanto el artículo $2^{\circ}$ de nuestra Constitución como en el Convenio 169 de la OIT sobre Pueblos Indígenas y Tribales en Países Independientes, donde se señala el derecho a la consulta previa, libre e informada que tienen los pueblos indígenas respecto de todas aquellas cuestiones que afecten sus tierras y territorios; la constante, sin embargo, son las denuncias de la venta/cesión de tierras comunales y ejidales sin el consentimiento de comuneros y ejidatarios.

Estos contratos, además, permiten la construcción y operación de las torres de aerogeneradores sin restricción alguna, conjuntamente con todas las instalaciones e infraestructura necesarias (Guijarro et al., 2009). Son innumerables los casos en los que, sin contrato de por medio, se han invadido terrenos y colocado las torres, ya que muchos de ellos se valen de argucias legales como la no distinción entre fincas productivas y terrenos baldíos. Muchas veces los terrenos son invadidos por "pajareros", quienes cumplen la tarea de retirar aves muertas en las inmediaciones de los aerogeneradores (Agatón et al., 2016); a esto se le suma la cooptación de representantes comunitarios y la simulación de asambleas ejidales con firmas de personas fallecidas y otras más que no aparecen en el padrón ejidal (Castillo, 2012).

De ahí que, de acuerdo con la visión de los afectados, son solo las grandes firmas quienes salen beneficiadas con la construcción de los parques eólicos (Agatón et al., 2016), ya que la energía producida no llega a la comunidad, sino que es administrada y transportada para las empresas que representan, por lo que varias organizaciones han pedido la nulidad de los contratos y la suspensión de los parques eólicos, o bien, la reestructuración de las normas que legitiman las formas de propiedad y valorización tanto de la tierra como del recurso eólico, así como una medición metódica de las profundas afectaciones ambientales que han repercutido en el aparato productivo agrícola del cual dependen (Castillo, 2012). 
Diferentes organismos ${ }^{16}$ así como diversas organizaciones indígenas ${ }^{17}$ han documentado una enorme cantidad de violaciones a los derechos humanos en este proceso: desde la falta de información verídica acerca de la naturaleza del proyecto hasta actos de violencia entre aquellos que se han opuesto al proyecto o que se niegan a firmar (Castillo, 2012). A su vez, la desinformación genera confusión entre la población, dividiendo las opiniones y generando un ambiente de confrontación al interior que rompe con las dinámicas sociales de comunalidad que definen a estas culturas.

Por último, nos gustaría resaltar cómo se ha dado el proceso de afectación en los terrenos, la cual ha sido visibilizada por activistas y organizaciones sociales; en el poblado de La Venta, perteneciente al municipio de Juchitán, los parques eólicos Eurus y Oaxaca III, propiedad de la empresa española Acciona, con 167 aerogeneradores y cuya principal generación eléctrica abastece a la empresa cementera CEMEX desde 2009, han sido denunciadas por el derrame continuo de aceite en sus aspas y en la bobina principal, lo cual ha causado contaminación al subsuelo y al agua de los campesinos y ganaderos que tienen ranchos aledaños al lugar.

En los dos parques eólicos existen turbinas con potencial de 1.500 $\mathrm{Mw}$, las cuales ocupan 400 litros de aceite sintético, mientras que los de $800 \mathrm{Mw}$, ocupan 200 litros de aceite por cada aerogenerador por año (Navarro y Bessi, 2014). Los pobladores locales, campesinos en su gran mayoría, indican que el derrame de aceite sintético, solventes y pinturas en el mantenimiento de los aerogeneradores afectan de manera significativa el suelo (Agatón et al., 2016), golpeando directamente su producción agrícola, su abastecimiento y su estilo de vida.

\section{Conclusiones}

La velocidad con la que los seres humanos nos acercamos a los puntos de inflexión señalados por los expertos del IPCC obliga a la toma de decisiones radicales, en especial en temas donde el estilo de vida y la

16 Centro de Derechos Humanos Tepeyac, Grupo Solidario La Venta, La Ventosa Vive, entre otros.

17 Unión de Comunidades Indígenas de la Zona Norte del Istmo (UCIZONI), Asamblea en Defensa de la Tierra, Asamblea en Defensa de la Tierra y Territorio de Juchitán, el Consejo de Ancianos de Ranchu Gubiña, entre otros. 
relación que mantenemos con el sistema natural nos ha colocado en encrucijadas con pocas opciones. La transformación de la matriz energética debería ser una prioridad en las políticas públicas de todas las naciones alrededor del mundo, eliminando la dependencia energética fósil y optimizando aquellas que apuesten por las energías renovables.

México, en ese sentido, posee un potencial que permitiría pensar en ese tránsito de manera diseñada y no por colapso. Los estudios de proyección de aprovechamiento eólico, calórico y de biomasa aseveran que, por sus características geográficas, geológicas y climatológicas, México posee elementos suficientes para revertir la pobreza energética en la que se encuentran poblaciones completas, además de cumplir con sus compromisos internacionales pactados y reducir así su aportación a la huella ecológica global.

Pese al abordaje de este escenario bajo la tutela estatal, la constante alrededor de la puesta en marcha de megaproyectos para el aprovechamiento sustentable de las condiciones naturales que en algunas regiones poseemos y la generación de energía a través de ellas es la respuesta de los pobladores quienes constantemente visibilizan las constantes violaciones a sus derechos humanos, al despojo biocultural, al resquebrajamiento del tejido social de sus comunidades debido a la forma cómo operan las centrales eólicas, la invasión a sus territorios a través de tácticas opresoras, intimidatorias, con verdades a medias, promesas incumplidas y compra de voluntades. Diversos colectivos, organismos especializados y activistas se han unido y solidarizado ante este escenario y denuncian constantemente los procedimientos ilegales utilizados por las empresas para poder llevar a cabo sus megaproyectos en menoscabo de la identidad, la cultura, las tradiciones y costumbres de los pueblos originarios quienes, desde su cosmovisión, denuncian la ruptura del equilibrio que su estilo de vida tiene con sus territorios, como consecuencia de la introducción de sistemas tecnocientíficos.

Por su parte, especialistas, investigadores y defensores de la tierra han documentado la importancia ecosistémica de la región del Istmo y su lenta degradación ante fenómenos como el crecimiento de las manchas urbanas o, en este caso, su explotación. Hay graves procesos de degradación, la cada vez más constante documentación de muerte de avifauna por colisión con los aerogeneradores al ser una importante ruta migratoria de millones de aves al año, la contaminación de suelos 
por el derrame de aceites, así como la afectación agrícola por el desmonte y la introducción de infraestructura.

Si bien es cierto que la necesaria diversificación de la matriz energética en México es urgente, esta debe encontrar mecanismos de inclusión de las comunidades en la toma de decisiones sobre sus territorios, ya que esta se ha hecho bajo la lógica mercantil que impone el sistema económico dominante, un sistema que cosifica y monetiza a la naturaleza, en contraposición a la cosmovisión de los pobladores originales, quienes encuentran en su territorio la raíz de su identidad, de su cultura y de su sentido de comunidad.

En ese sentido, la búsqueda de alternativas a la matriz energética fósil debe necesariamente generar espacios para la cogeneración de conocimientos con aquellos que habitan estos territorios, a quienes sistemáticamente se les excluye de la toma de decisiones por querer preservar su visión no occidentalizada del aprovechamiento de los recursos. La justicia energética señalada en los ODS de Naciones Unidas no podrá alcanzarse si esta premisa sigue pendiente.

\section{Referencias}

Agatón, G., Santiago, A., Sautto, M., y Montaño, A. (2016). Estudio de impacto ambiental, económico y social en la región del Istmo de Tehuantepec, Oaxaca, México, debido a la instalación de parques eólicos. Tlamati, 7(1), 14-21. Recuperado de http://tlamati.uagro.mx/t71/tlamati71.pdf

Altamirano, M., Martín, F., y Cartas, G. (2001). Ocurrencia, distribución y abundancia del género Passerina en la reserva de la biosfera La Sepultura, Chiapas. Acta Sociológica Mexicana, 85, 169-180. Recuperado de http://www.scielo.org.mx/scielo. php?script=sci_arttext\&pid=S0065-17372002000100011

Ayuntamiento de Dúrcal, Adurcal. (s/f). Las amenazas inducidas por los parques eólicos. Recuperado de http://adurcal.com/enlaces/mancomunidad/viabilidad/59.htm

Barragán, D. (2015). Parques eólicos: la cara del despojo en el Istmo de Tehuantepec. Recuperado de https://www.sinembargo. $\mathrm{mx} / 01-04-2015 / 1298234$

Beltrán, A., Morera, M., López, F., y Villeda, R. (2017). Prospectiva de las energías eólica y solar fotovoltaica en la producción de 
energía eléctrica. Ciencia UAT, 11(2), 105-117. Recuperado de https://www.redalyc.org/pdf/4419/441949672008.pdf

Brown, K. (2013). Global environmental change I: A social turno for resilience? Progress in Human Geography, 38(1), 107-117. https://doi.org/10.1177/0309132513498837

Cabrera, S., Mabee, T., y Villegas, R. (2017). Patterns of nocturnal bird migration in southern Mexico. Revista Mexicana de Biodiversidad, 88(4), 867-879. https://doi.org/10.1016/j. rmb.2017.10.027

Castillo, E. (2011). Las implicaciones socioambientales de la producción de energía eólica. Recuperado de https://omal.info/spip. php?article903\&debut_agenda $=4$

Castillo, E. (2012). Problemática en torno a la construcción de parques eólicos en el Istmo de Tehuantepec. Desarrollo Local Sostenible, 4(12), 1-14. Recuperado de http://www.nacionmulticultural.unam.mx/mezinal/docs/4797.pdf

Ceballos, G. y Martínez, L. (2010). Mamíferos. En G. Ceballos, L. Martínez, A. García, E. Espinoza, J. Bezaury, y R. Dirzo (Eds.), Diversidad, amenazas y áreas prioritarias para la conservación de las selvas secas del Pacífico de México (pp. 119-144). México, D.F.: Fondo de Cultura Económica, Comisión Nacional para el Conocimiento y Uso de la Biodiversidad, Conabio.

Comisión Nacional para el Conocimiento y Uso de la Biodiversidad, Conabio. (2004). Áreas de Importancia para la Conservación de las Aves, AICAS. México D.F.: Comisión Nacional para el Conocimiento y Uso de la Biodiversidad, Conabio. Recuperado de http://conabioweb.conabio.gob.mx/aicas/doctos/aicas.html

Comisión Nacional para el Conocimiento y Uso de la Biodiversidad, Conabio. (2020). Atlas de Naturaleza y Sociedad. México, D.F.: Comisión Nacional para el Conocimiento y Uso de la Biodiversidad, Conabio.

Cortés-Marcial, M. y Briones-Salas, M. (2014). Diversidad, abundancia relativa y patrones de actividad de mamíferos medianos y grandes en una selva seca del Istmo de Tehuantepec, Oaxaca, México. Revista de Biología Tropical, 62(4), 1433-1488. https://doi.org/10.15517/rbt.v62i4.13285

Dahl, E., Bevanger, K., Nygard, T., Roskaft, E., y Stokke, B. (2012). Reduced breeding success in withe-tailed eagles at Smola Windfarm, Western Norway, is caused by mortality and dis- 
placement. Biological Conservation, 145(1), 79-85. https:// doi.org/10.1016/j.biocon.2011.10.012

Desinformemonos.org (2019). Los Ikoots y la defensa de su territorio: 10 años de resistencia desde la atarraya y el telar en Oaxaca. Recuperado de https://desinformemonos.org/los-ikoots-yla-defensa-de-su-territorio-10-anos-de-resistencia-desdela-atarraya-y-el-telar-en-oaxaca/

Déniz, J., De la Rosa, E., y Verona, C. (2012). El impacto social de las compañías de energía eólica españolas en las comunidades campesinas de Oaxaca y su reflejo en las memorias de sostenibilidad. Recuperado de http://congreso.investiga.fca.unam. $\mathrm{mx} /$ docs/xvii/docs/J02.pdf

Díaz, E. (2015). Energía eólica y conflicto social en el Istmo de Tehuantepec, Oaxaca, México. Recuperado de http://www.ub.edu/ geocrit/iii-mexico/DiazCarnero.pdf

Diego, R. (2017). Política gubernamental vs. política pública: avatares de los parques eólicos en el Istmo de Tehuantepec. Problemas del Desarrollo, 194(49), 91-117. https://doi.org/10.22201/ iiec.20078951e.2018.194.61586

Drewitt, A. y Langston, R. (2006). Assessing the impacts of wind farms on birds: Impacts of wind farms on birds. Biological Conservation, 148(s1), 29-42. https://doi.org/10.1111/j.1474919x.2006.00516.x

Duchamp, M. (2004). Energía eólica. Los efectos negativos de las centrales eólicas. Ibérica 2000. Recuperado de http://www.iberica2000.org/Es/Articulo.asp?Id=1272

Durán, N., Ruiz, J., González, D., y Martínez, J. (2020). Descriptores ecológicos y efectos del cambio climático en la aptitud ambiental de Leucaena leucocephala (Lam.) de Wit. Revista Mexicana de Ciencias Forestales, 11(59), 1-22. https://doi. org/10.29298/rmcf.v11i59.670

Elliot, D., Schwartz, M., Scott, G., Haymes, S., Heimiller, D., y George, R. (2014). Atlas de recursos eólicos del estado de Oaxaca. Recuperado de https://www.nrel.gov/docs/fy04osti/35575.pdf

El Financiero (2018). Parques eólicos en México. Recuperado de https:// www.elfinanciero.com.mx/pages/docs/parques-eolicosen-mexico.html

El Universal (2011). Las trampas de las energías limpias. Recuperado de https://archivo.eluniversal.com.mx/cultura/65449.html 
El Universal (2018). Oaxaca es hábitat de 5 especies de felinos. Recuperado de https://oaxaca.eluniversal.com.mx/especiales/22-08-2018/oaxaca-es-habitat-de-5-especies-de-felinos

El Universal (2020a). En Oaxaca se produce el 62\% de la energía eólica generada en el país. Recuperado de https://oaxaca.eluniversal.com.mx/estatal/06-01-2020/en-oaxaca-se-produce-el62-de-la-energia-eolica-generada-en-el-pais

El Universal (2020b). Mujeres ikoots solicitan medidas cautelares por violencia en San Mateo del Mar; acusan a agente municipal. Recuperado de https://oaxaca.eluniversal.com.mx/sociedad/05-05-2020/mujeres-ikoots-solicitan-medidas-cautelares-por-violencia-en-san-mateo-del-mar

Elías, E. (s/f). Las aves migratorias: un recurso compartido en el Continente Americano y su relación con el Istmo de Tehuantepec. Recuperado de https://www.academia.edu/4344274/ aves_tehuantepec

Energías Renovables. (2012). Entre seis y 18 millones de aves muertas cada año. Recuperado de https://www.energias-renovables. com/eolica/entre-seis-y-dieciocho-millones-de-aves

European Commission (2015). Paris agreement. Recuperado de https://ec.europa.eu/clima/policies/international/negotiations/paris_en

Forbes México (2020). La industria eólica mexicana: ¿tan destructiva como los combustibles fósiles? Recuperado de https://www. forbes.com.mx/negocios-industria-eolica-mexico-combustibles-fosiles/

Garvin, J., Jennelle, C. Drake, D., y Grodsky, S. (2011). Response of raptors to a wind farm. Journal of Applied Ecology, 48(1), 199209. https://doi.org/10.1111/j.1365-2664.2010.01912.x

García-Trejo, E. y Navarro, A. (2004). Patrones biogeográficos de la riqueza de especies y el endemismo de la avifauna en el oeste de México. Acta Zoológica Mexicana, 20(2), 167-185. Recuperado de http://www.scielo.org.mx/pdf/azm/v20n2/ v20n2a11.pdf

González, G., Ossa, G., Silva, R., y Sánchez, L. (2014). Medidas de mitigación de impactos en aves silvestres y murciélagos. Información sistematizada nacional e internacional. Documento de trabajo. Recuperado de http://www.sag.cl/sites/default/ files/producto_ii_v3.pdf 
Grunstein-Dickter, M. (2016). Contra el viento: regulación, crisis social y cambio institucional en el Corredor Eólico del Istmo. Economía, Sociedad y Territorio, 16(51), 485-517. https://doi. org/10.22136/est002016851

Guijarro, A., Lumbreras, J., Habert, J., y Guereña, A. (2009). Impacto de los proyectos MDL sobre el desarrollo humano. Informe de investigación. Madrid: Grupo de Cooperación en Organización, Calidad y Medio Ambiente, Universidad Politécnica de Madrid.

Hall, I. (2017). De la colectividad a la comunidad. Reflexiones acerca del derecho de propiedad en Llanchu, Perú. Revista de Antropología Social, 26(2), 379-398. https://doi.org/10.5209/ raso.57611

Henestroza, R. (2009). Centrales eólicas en el Istmo de Tehuantepec; su impacto ambiental y socioeconómico. Elementos: Ciencia y Cultura, 16(74), 39-44. Recuperado de https://www.redalyc. org/pdf/294/29411994005.pdf

Howe, C. y Boyer, D. (2015). Los márgenes del Estado al viento: autonomía y desarrollo de energías renovables en el sur de México. The Journal of Latin American and Caribbean Anthropology, 20(2), 1-23. https://doi.org/10.1111/jlca.12149

Instituto Nacional de Estadística y Geografía, INEGI. (2012). Mapa Digital de México. México, D.F.: Instituto Nacional de Estadística y Geografía.

Instituto Nacional de Estadística y Geografía, INEGI. (2015). Panorama sociodemográfico de Oaxaca. México, D.F.: Instituto Nacional de Estadística y Geografía.

Instituto Tecnológico del Istmo, ITI. (2016). Eólicos. Trampas para aves migratorias. Recuperado de http://www.istmopress.com. $\mathrm{mx}$ /especiales/eolicos-trampas-aves-migratorias/

Juárez-Hernández, S. y León, G. (2014). Energía eólica en el Istmo de Tehuantepec: desarrollo, actores y oposición social. Revista Problemas del Desarrollo, 45(178), 139-162. https://doi. org/10.1016/s0301-7036(14)70879-x

Kaldellis, J., Apostolou, D., Kapsali, M., y Kondili, E. (2016). Environmental and social footprint of offshore wind energy. Comparison with onshore counterpart. Renewable Energy, 92, 543-556. https://doi.org/10.1016/j.renene.2016.02.018 
Lontzek, T., Cai, Y., Judd, K., y Lenton, T. (2015). Stochastic integrates assessment of climate tipping points indicates the need for strict climate policy. Nature Climate Change, 5(5), 441-444. https://doi.org/10.1038/nclimate2570

Naturalista. (2018). Aves del sr del Istmo de Tehuantepec, Oaxaca, México. Recuperado de https://www.naturalista.mx/projects/ aves-del-sur-del-istmo-de-tehuantepec-oaxaca

Navarro, S. y Bessi, R. (2014). Rastros obscuros de la energía limpia en Oaxaca, México. Recuperado de https://subversiones.org/ archivos/121716

Navarro, S. (2014). El Istmo, en riesgo ambiental por los parques eólicos. Recuperado de https://www.somosmass99.com.mx/elitsmo-en-riesgo-ambiental-por-parques-eolicos/

Organización de las Naciones Unidas, ONU. (2015). Objetivos de Desarrollo Sostenible. Recuperado de https://www.un.org/sustainabledevelopment/es/objetivos-de-desarrollo-sostenible/

Oroschakoff, K. (2018). Small old wind towers make for big new problems. Recuperado de https://www.politico.eu/article/small-old-wind-towers-make-for-big-new-problems/?fbclid=IwAR2-iGNJqk3hIgPcWk2lK-AYicS4LM6jIRLt5fujFNZj5uEtEzf9nOENiaI

Oswald, Ú. (2017). Seguridad, disponibilidad y sustentabilidad energética en México. Revista Mexicana de Ciencias Políticas y Sociales, 62(230), 155-195. https://doi.org/10.1016/s01851918(17)30020-x

Philofauna. (s/f). Portada. Recuperado de https://sites.google.com/ site/philofauna/

Powleslan, R. (2010). Impacts of wind farms on birds: A review. Recuperado de https://www.doc.govt.nz/Documents/science-andtechnical/sfc289entire.pdf

Process Industry Forum (s/f). Advantages and Disadvantages of Wind Power. Recuperado de https://www.processindustryforum. com/energy/advantages-disadvantages-of-wind-power

Puyana, A. (2015). La economía petrolera en un mercado politizado global. México y Colombia. México, D.F.: Facultad Latinoamericana de Ciencias Sociales, FLACSO México.

Sánchez, W. (2010). El potencial eólico del Istmo de Tehuantepec y su impacto en los derechos humanos. Recuperado de https:// www.researchgate.net/publication/312316198_El_poten- 
cial_eolico_del_Istmo_de_Oaxaca_y_su_impacto_en_los_ derechos_humanos

Secretaría de Energía, Sener. (2012a). Prospectiva de energías renovables 2012-2026. Recuperado de http://www.sener.gob.mx/ res/PE_y_DT/pub//2012/PER_2012-2026.pdf

Secretaría de Energía (Sener) (2012b). Prospectiva del sector eléctrico 2012-2026. Recuperado de http://www.sener.gob.mx/res/ PE_y_DT/pub/2012/PSE_2012_2026.pdf

Secretaría de Gobernación, Segob. (2015). La energía eólica en México. México, D.F.: Secretaría de Gobernación, Segob.

Secretaría del Medio Ambiente, Energías y el Desarrollo Sustentable, Semaedeso. (s/f). Energía eólica. Recuperado de https:// www.oaxaca.gob.mx/semaedeso/energia-eolica/

Secretaría del Medio Ambiente, Energías y el Desarrollo Sustentable, Semaedeso. (2016). Generadores autorizados. Recuperado de https://www.oaxaca.gob.mx/semaedeso/permisos-degeneracion-de-energia/

Seoane, J. (2012). Neoliberalismo y ofensiva extractivista. Actualidad de la acumulación por despojo, desafíos de Nuestra América. Theomai, 26, 1-27. Recuperado de https://www.redalyc. org/pdf/124/12426097006.pdf

Servicio Internacional para la Paz, Sipaz. (2013). ENFOQUE: Impactos $y$ afectaciones de los proyectos de energía eólica en el Istmo de Tehuantepec. Recuperado de http://www.sipaz.org/enfoque-impactos-y-afectaciones-de-los-proyectos-de-energiaeolica-en-el-istmo-de-tehuantepec/\#vsiete

Sistema Nacional de Información sobre Biodiversidad, SNIB. (2020). Portal de georreferenciación. Recuperado de http://www.conabio.gob.mx/informacion/gis/

Toledo, V. (2013). El metabolismo social: una nueva teoría socioeconómica. Relaciones. Estudios de historia y sociedad, 136, 41-71. Recuperado de http://www.scielo.org.mx/scielo. php?pid=S0185-39292013000400004\&script=sci_arttext

Toledo, V. y Barrera-Bassols, N. (2008). La memoria biocultural. La importancia ecológica de las sabidurías tradicionales. Barcelona: Icaria editorial.

Uharte, L. (2015). Las multinacionales en el siglo XXI: impactos múltiples. El caso de Iberdrola en México y Brasil. Recuperado de 
https://omal.info/IMG/pdf/multinacionales_en_el_siglo_ xxi_impactos_multiples.pdf

Uribe-Rivera, M., Guevara-Carrizales, A., y Ruiz-Campos, G. (2019). Mortalidad incidental de aves paseiformes en un parque eólico del noreste de México. Huitzil, Revista Mexicana de Ornitología, 20(1), 1-7. https://doi.org/10.28947/ hrmo.2019.20.1.377

Vázquez, L., Moya, H., y Arizmendi, M. (2009). Avifauna de la selva baja caducifolia en la cañada del río Sabino, Oaxaca, México. Revista Mexicana de Biodiversidad, 80, 535-549. https://doi. org/10.22201/ib.20078706e.2009.002.626

Villegas, R. y Herrera, L. (2015). Migration of Franklin's Gull (Leucophaeus pipixcan) and its variable annual risk from wind power facilities across the Tehuantepec Isthmus. Journal for Nature Conservation, 25, 72-76. https://doi.org/10.1016/j. jnc.2015.03.006

Wang, S. y Wang, S. (2015). Impacts of wind energy on environment: A review. Renewable and Sustainable Energy Reviews, 49, 437443. https://doi.org/10.1016/j.rser.2015.04.137

Zárate, E. y Fraga, J. (2015). La política eólica mexicana: controversias sociales y ambientales debido a su implantación territorial. Estudios de caso en Oaxaca y Yucatán. Trace, 69, 65-95. https://doi.org/10.22134/trace.v0i69.10 